\title{
The progressive elevation of alpha fetoprotein for the diagnosis of hepatocellular carcinoma in patients with liver cirrhosis
}

\author{
Oscar Arrieta*1,3, Bernardo Cacho ${ }^{\dagger 2}$, Daniela Morales-Espinosa ${ }^{\dagger 1}$, \\ Ana Ruelas-Villavicencio ${ }^{2}$, Diana Flores-Estrada ${ }^{1}$ and Norma Hernández- \\ Pedro $^{1}$
}

\begin{abstract}
Address: ${ }^{1}$ Department of Medical Oncology, Instituto Nacional de Cancerología (INCan), Mexico City, Mexico, ${ }^{2}$ Department of Internal Medicine, Instituto Nacional de Ciencias Médicas y Nutrición "Salvador Zubirán" (INCMNSZ), Mexico City, Mexico and 3Universidad Nacional Autónoma de México (UNAM), Mexico City, Mexico

Email: Oscar Arrieta* - ogar@servidor.unam.mx; Bernardo Cacho - bernardocacho@ doctor.com; Daniela Morales-

Espinosa - danamores@yahoo.com; Ana Ruelas-Villavicencio - lemlogar@hotmail.com; Diana Flores-Estrada - dfe15@yahoo.com.mx;

Norma Hernández-Pedro - noryhp@hotmail.com

* Corresponding author †Equal contributors
\end{abstract}

Published: 8 February 2007

BMC Cancer 2007, 7:28 doi:10.1 I86/147|-2407-7-28
Received: 10 March 2006

Accepted: 8 February 2007

This article is available from: http://www.biomedcentral.com/147I-2407/7/28

(c) 2007 Arrieta et al; licensee BioMed Central Ltd.

This is an Open Access article distributed under the terms of the Creative Commons Attribution License (http://creativecommons.org/licenses/by/2.0), which permits unrestricted use, distribution, and reproduction in any medium, provided the original work is properly cited.

\begin{abstract}
Background: Hepatocellular carcinoma is the most common cause of primary liver neoplasms and is one of the main causes of death in patients with liver cirrhosis. High Alpha fetoprotein serum levels have been found in $60-70 \%$ of patients with Hepatocellular carcinoma; nevertheless, there are other causes that increase this protein. Alpha fetoprotein levels $\geq 200$ and $400 \mathrm{ng} / \mathrm{mL}$ in patients with an identifiable liver mass by imaging techniques are diagnostic of hepatocellular carcinoma with high specificity.
\end{abstract}

Methods: We analysed the sensitivity and specificity of the progressive increase of the levels of alpha fetoprotein for the detection of hepatocellular carcinoma in patients with liver cirrhosis. Seventy-four patients with cirrhosis without hepatocellular carcinoma and 193 with hepatic lesions diagnosed by biopsy and shown by image scans were included. Sensitivity and specificity of transversal determination of alpha fetoprotein $\geq 200$ and $400 \mathrm{ng} / \mathrm{mL}$ and monthly progressive elevation of alpha fetoprotein were analysed. Areas under the ROC curves were compared. Positive and negative predictive values adjusted to a 5 and $10 \%$ prevalence were calculated.

Results: For an elevation of alpha fetoprotein $\geq 200$ and $400 \mathrm{ng} / \mathrm{mL}$ the specificity is of $100 \%$ in both cases, with a sensitivity of 36.3 and $20.2 \%$, respectively. For an alpha fetoprotein elevation rate $\geq 7 \mathrm{ng} / \mathrm{mL} / \mathrm{month}$, sensitivity was of $71.4 \%$ and specificity of $100 \%$. The area under the ROC curve of the progressive elevation was significantly greater than that of the transversal determination of alpha fetoprotein. The positive and negative predictive values modified to a $10 \%$ prevalence are of: $98.8 \%$ and $96.92 \%$, respectively; while for a prevalence of $5 \%$ they were of $97.4 \%$ and $98.52 \%$, respectively.

Conclusion: The progressive elevation of alpha fetoprotein $\geq 7 \mathrm{ng} / \mathrm{mL} / \mathrm{month}$ in patients with liver cirrhosis is useful for the diagnosis of hepatocellular carcinoma in patients that do not reach $\alpha F P$ levels $\geq 200 \mathrm{ng} / \mathrm{mL}$. Prospective studies are required to confirm this observation. 


\section{Background}

Hepatocellular carcinoma (HCC) is the most common cause of primary liver neoplasms and the fourth most frequent type of cancer worldwide with an increasing incidence, causing one million deaths per year[1]. Nowadays, therapeutic options are still not efficient, reaching a global survival rate of $3-10 \%$ at 5 years after diagnosis. The major risk factors associated to the development of HCC are infection with hepatitis $\mathrm{B}$ virus (HBV), hepatitis $\mathrm{C}$ virus (HCV) and cirrhosis of any cause[2]. HCC is one of the main causes of death in patients with Liver Cirrhosis (LC)[3]. The annual risk to develop HCC in patients with LC is $5 \%(1-7 \%)$, with a published prevalence between 7.4 and $23 \%$ found in necropsies of this group of patients. Cirrhosis is present in $80-90 \%$ of patients with this type of cancer [3].

Alpha-fetoprotein $(\alpha \mathrm{FP})$ is a protein of fetal component produced during the embryonic period by the visceral endoderm of the gestational sac and, later on, by the liver. Its re-expression in patients with HCC has been described for over 40 years. Some studies have demonstrated that the presence of elevated levels of $\alpha$ FP in patients with LC is a risk factor for the development of HCC [4-6], thus suggesting that increased $\alpha \mathrm{FP}$-production in patients with LC might reflect, largely and abnormal or altered liver cell regeneration. High $\alpha \mathrm{FP}$ serum levels have been found in $60-70 \%$ of patients with HCC; nevertheless, there are other causes of increased levels, such as cirrhosis, lung cancer, biliary cancer, gastric cancer, pancreatic cancer, teratocarcinoma of the testis, spherocytosis and tyrosinemia[7]. Alpha fetoprotein levels $<20 \mathrm{ng} / \mathrm{mL}$ are considered normal; with this value as the upper level, this diagnostic test has a sensitivity of $41-65 \%[4,8,9]$ to diagnose HCC, but a low specificity. The $\alpha F P$ levels diagnostic for HCC are above $400 \mathrm{ng} / \mathrm{mL}[10]$ in patients with LC and a solid liver mass $>2 \mathrm{~cm}$ with typical features in one imaging study. The Italian and the American Association for the Study of Liver Diseases guidelines consider a level $\geq 200 \mathrm{ng} / \mathrm{mL}$ as the cut-off point for diagnosis [8,9,11-13]. Higher levels of $\alpha \mathrm{FP}$ are associated with poor prognostic and survival rates in untreated patients with HCC or those treated with liver transplantation or locoregional therapies $[4,8,14]$. Some experts use $\alpha$ FP determinations and liver ultrasound every 3 to 6 months to detect HCC in patients with liver disease[15-17].

There is no concluding evidence available of the changes of $\alpha$ FP levels throughout the disease yet[18]. The aim of our study was to evaluate the progressive elevation of $\alpha \mathrm{FP}$ as a diagnostic test in patients with LC with an hepatic lesion suspicious of HCC, and compare it to the transversal determination of $\alpha \mathrm{FP} \geq 200$ and $400 \mathrm{ng} / \mathrm{mL}$.

\section{Methods}

This study was carried out in a single reference center (Instituto Nacional de Ciencias Médicas y Nutrición "Salvador Zubirán", National Institute of Medical Sciences and Nutrition) the patients were studied in the time period comprehended between January 1992 and December 2002, in the out-patient clinics of the Internal Medicine and Gastroenterology services. Patients with the diagnosis of LC and serial monthly determinations of $\alpha \mathrm{FP}$ levels, were included; the presence of cirrhosis was established by biopsy or clinical data of chronic liver disease, complications such as portal hypertension, esophageal varices with or without a previous episode of bleeding, splenomegaly, ascites with a previous episode of spontaneous bacterial peritonitis in the absence of other non hepatic causes, hepatic encephalopathy in the absence of other metabolic causes, hypoalbuminemia or hyperbilirubinemia in the absence of a known cause of the obstruction of the bile duct of at least one year of appearance with progressive liver failure. All patients in the control group had a minimal follow-up of one year with monthly determination of serum $\alpha$ FP levels and imaging studies every 3 to 6 months in order to assess they did not have HCC. Ultrasound, Computed Tomography and Magnetic Resonance Imaging were the diagnostic studies employed in this work, the use of one or another depended on the treating physicians' personal preferences.

Patients who were diagnosed with HCC by biopsy and had monthly determinations of $\alpha F P$ levels were included as cases. Patients in which the diagnosis of HCC was performed by other means (e.g. alternative methods of imaging diagnosis) were excluded. Files from the clinical archive were reviewed. The exclusion criteria were: patients with incomplete files, patients who did not meet diagnosis criteria for LC or HCC, patients who were misdiagnosed, or who did not have at least three serial monthly determinations of the levels of $\alpha \mathrm{FP}$ reported. A database was done registering clinical and pathological information. All patients were classified based on the Child-Pugh-Turcotte criteria (based on serum bilirubin and albumin, ascites, neurological disorder and nutrition), which are established prognostic factors in patients with liver cirrhosis undergoing surgery $[19,20]$.

The comparison of the clinical and pathological characteristics between patients with and without an elevation of $\alpha \mathrm{FP} \geq 200$ and $400 \mathrm{ng} / \mathrm{mL}$, as well as between those with and without progressive elevation was done with student's T test and Mann-Whitney's U for continuous variables with and without normal distribution, respectively. For comparisons between more than three variables, ANOVA and Tukey correction tests were used. Qualitative variables were compared with Chi squared and exact Fisher's test. A p value $<0.05$ was considered as significant. 
Sensitivity (i.e. True Positive Rate) and specificity (i.e. True Negative Rate) were obtained by determining the levels of $\alpha \mathrm{FP}$ and its progressive elevation (the average monthly increase of at least three measurements was required), using SPSS statistical software version 10.0.

The Receiving Operating Characteristic (ROC) Analysis curves and the corresponding area under the curve were calculated to provide the accuracy of serum $\alpha F P$ in differentiating HCC and LC patients. Non-parametric estimates of the area under the ROC curve and the respective standard error were applied. Positive (PPV) and Negative (NPV) predictive values were evaluated in our study considering a prevalence of HCC of 5 and $10 \%$. This was done with EPIDAT software version 3.

The experimental research reported in this manuscript has been performed with the approval of the Institutional Review Board and Ethics Committee of the National Institute of Medical Sciences and Nutrition and is in compliance with the Helsinki Declaration.

\section{Results}

We obtained 212 files of patients with the diagnosis of HCC and 202 of patients with LC; from which 193 and 74 patients were included, respectively. The main causes of exclusion were: incomplete files, lack of $\alpha \mathrm{FP}$ determinations, and an ambiguous diagnosis. No differences were found among the patients considered as controls and those excluded with LC regarding female gender ( 60 vs $63 \%, \mathrm{p}=0.9)$, age $(51.7 \pm 1.7$ vs $50.7 \pm 2$ years; $\mathrm{p}=0.8)$, Child (A/B/C 40/42/18 vs 55/34/11\%, $\mathrm{p}=0.4$ ) and etiology (alcoholic 11.2 vs 14 , HCV 45 vs 50, cryptogenic 32 vs $15.9 \mathrm{p}=0.5)$, serum $\alpha$ FP levels $(8.2 \pm 2.2$ vs $13 \pm 4.4$ $\mathrm{ng} / \mathrm{mL}, \mathrm{p}=0.3$ ). This analysis included only 85 of the excluded patients due to an insufficient accuracy of the medical files.

The minimal follow-up time of the patients with LC without HCC (control cases) was of one year. The median follow-up time of the patients with HCC was of $4.5 \pm 1.2$ months. Seventy-five percent of the patients with HCC had a tumor size $>5 \mathrm{~cm}$. Tumors were multicentric in $22 \%$ and poorly differentiated in 35\%. General characteristics of patients with HCC and LC are described in Table 1. We found a greater proportion of men and a greater mean age for patients with HCC. No differences regarding the Child-Pugh score were found between groups. The $\alpha \mathrm{FP}$ level was significantly higher for patients with HCC compared to patients with LC $(8.2 \pm 2.2 \mathrm{vs} 271 \pm 46 \mathrm{ng} / \mathrm{mL}$, respectively, $p<0.001$ ). The progressive elevation of $\alpha F P$ was greater in patients with HCC when compared to patients with LC $(0.34 \pm 0.2$ vs $62.3 \pm 13.5 \mathrm{ng} / \mathrm{mL} / \mathrm{month}$, respectively, $p<0.001$ ) (Table 1 ). No differences were found between the $\alpha \mathrm{FP}$ elevation and the Child-Pugh score, age, gender, etiology, differentiation grade and tumour size amongst patients with HCC (Table 2). All patients of both groups have at least 3 determinations of $\alpha F P$. The median number of $\alpha F P$ determinations was of 3 , range from 3 to 5 in both groups. The average increase of the levels of $\alpha \mathrm{FP}$ in patients with $\alpha \mathrm{FP}$ basal levels $<20 \mathrm{ng} /$ $\mathrm{mL}$ was of $15.8 \mathrm{ng} / \mathrm{mL} \pm$ STD error $10.7,67.9 \mathrm{ng} / \mathrm{mL} \pm 38$ in the patients with a basal $\alpha \mathrm{FP}$ level between 20 and 100 $\mathrm{ng} / \mathrm{mL}$, and $76.3 \mathrm{ng} / \mathrm{mL} \pm 18$ for the patients with $\alpha \mathrm{FP}$ levels $>200 \mathrm{ng} / \mathrm{mL}(\mathrm{p}=0.211)$. An elevation of $\alpha \mathrm{FP} \geq 7 \mathrm{ng} /$ $\mathrm{mL} / \mathrm{month}$ in one determination was observed in $16.4 \%$ and $70.8 \%$ of patients with LC and HCC, respectively; while $1.8 \%$ and $43.2 \%$ of patients with LC and HCC showed an elevation $\geq 7 \mathrm{ng} / \mathrm{mL} / \mathrm{month}$ in two determinations.

The sensitivity and specificity for the transversal determination of $\alpha F P$ varied according to its level as shown in Table 3. For an $\alpha$ FP elevation $\geq 200$ and 400 the specificity is of $100 \%$ in both cases, with a sensitivity of 36.3 and $20.2 \%$, respectively. The sensitivity and specificity for the progressive determination of $\alpha \mathrm{FP}$ are shown in Table 4 . In Figure 1, the areas under the ROC curves for the $\alpha F P$ levels and the progression of $\alpha \mathrm{FP}$ are shown. The area is significantly greater for the $\alpha$ FP progressive elevation group $(\mathrm{p}<$ 0.05 ). In patients with an $\alpha \mathrm{FP}$ progression rate $\geq 7 \mathrm{ng} / \mathrm{mL} /$ month a sensitivity of $71.4 \%$ and a specificity of $100 \%$ were found. We obtained an area under the curve of 0.587 with $\alpha \mathrm{FP}$ levels $\geq 200 \mathrm{ng} / \mathrm{ml}$, and 0.82 with the progressive elevation of $\alpha \mathrm{FP} \geq 7 \mathrm{ng} / \mathrm{mL} / \mathrm{month}, p<0.001$.

For patients with baseline $\alpha \mathrm{FP}$ levels $>7-20$, sensitivity, specificity, positive predictive value (PPV) and negative predictive values (NPV) were: 50, 100, 100 and 78.7\%, respectively. For those with $\alpha$ FP baseline levels from 21 to 100 , sensitivity, specificity, PPV and NPV were of 85,100 , 100 y $87.5 \%$, respectively; between 101 and 200, these values were of $50,100,100$ y $25 \%$, respectively.

Table 5 reports a PPV and NPV of $\geq 200$ and $400 \mathrm{ng} / \mathrm{mL}$, as well as for the progressive elevation of $\alpha \mathrm{FP} \geq 7 \mathrm{ng} / \mathrm{mL} /$ month taking into account a prevalence of 5 and $10 \%$. The positive and negative predictive values for the progressive elevation of $\alpha \mathrm{FP} \geq 7 \mathrm{ng} / \mathrm{mL} /$ month modified to a $10 \%$ prevalence are of: $98.8 \%$ and $96.92 \%$, respectively; while for a prevalence of $5 \%$ they were of $97.4 \%$ and $98.52 \%$, respectively. This PPV could be used to reveal the neoplastic nature of a liver mass occurring during surveillance in patients without a transversal elevation of $\alpha F P$.

\section{Discussion}

Many studies have evaluated the $\alpha F P$ serum levels as a diagnostic test for HCC in patients with LC[9]. Due to the poor prognosis of patients with HCC, in order to improve survival, the therapeutic approach mainly depends on an 
Table I: General characteristics of the patients with liver cirrhosis (LC) and hepatocellular carcinoma (HCC)

\begin{tabular}{|c|c|c|c|}
\hline Characteristics & LC & $\mathrm{HCC}$ & $P$ \\
\hline Female & $60 \%$ & $46 \%$ & 0.049 \\
\hline Male & $40 \%$ & $64 \%$ & \\
\hline Age & $51.7 \pm 1.7$ & $59.9 \pm 0.96$ & 0.001 \\
\hline \multicolumn{4}{|l|}{ Child-Pugh Score } \\
\hline A & $40 \%$ & $47 \%$ & \\
\hline B & $42 \%$ & $37.3 \%$ & 0.48 \\
\hline C & $18 \%$ & $15 \%$ & \\
\hline \multicolumn{4}{|l|}{ Etiology } \\
\hline Alcoholic & $11.2 \%$ & $26 \%$ & \\
\hline HBV & $0 \%$ & $7.2 \%$ & \\
\hline $\mathrm{HCV}$ & $45 \%$ & $30 \%$ & 0.001 \\
\hline Cryptogenic/autoimmune & $32 \%$ & $5.7 \%$ & \\
\hline Undetermined or absent & $11 \%$ & $30.4 \%$ & \\
\hline$\alpha \mathrm{FP}$ & $8.2 \pm 2.2$ & $271 \pm 46$ & 0.001 \\
\hline$\alpha \mathrm{FP}>400$ & $0 \%$ & $19.6 \%$ & 0.001 \\
\hline Progressive monthly elevation & $0.34 \pm .161$ & $62.3 \pm 13.5$ & 0.001 \\
\hline Increase of $5 \mathrm{ng} / \mathrm{mL} / \mathrm{month}$ or greater & $1.7 \%$ & $76.2 \%$ & 0.001 \\
\hline
\end{tabular}

early diagnosis. Besides being a diagnostic tool, determination of $\alpha \mathrm{FP}$ has also been used to evaluate the response to treatment and, moreover, to detect recurrences[10,21]; other studies have demonstrated that elevated levels of $\alpha F P$ are an independent risk factor for the development of HCC in patients with LC[5,6].

The causes of liver disease in our study were: alcoholic liver disease, infection with either hepatitis B or hepatitis $\mathrm{C}$ viruses, and cryptogenic (Table 1), as previously reported; but with a different frequency[22,23]. Studies have found differences in the $\alpha \mathrm{FP}$ levels related to: the tumoral size and tumor doubling time the Child-Pugh score and the age of patients with HCC[21,24,25]; however this was not corroborated either in our study, or by other authors[26-28]. Even though the patients in our study had a close follow-up, $75 \%$ were found to have large tumors $(>5 \mathrm{~cm})$. Although there are studies suggesting that an intensive surveillance program may identify smaller tumors, this is still controversial $[29,30]$. Furthermore, other studies have not found a statistically significant relationship between the positivity of $\alpha \mathrm{FP}$ and tumoral size, degree of vascular invasion and the histological differentiation grade of the tumor. Nevertheless, patients with positive staining for $\alpha \mathrm{FP}$ had a worse prognosis than those with negative staining [31].

The sensitivity and specificity of $\alpha \mathrm{FP}$ for the detection of HCC has been reported from 17 to $76 \%$ and 80 to $100 \%$, respectively (Table 6) $[8,18,32-36]$. We found that an $\alpha \mathrm{FP}$ value $\geq 200$ and $400 \mathrm{ng} / \mathrm{mL}$ has a sensitivity of $36.3 \%$ and $20.2 \%$, respectively, and specificity of $100 \%$ in both groups; a study with 340 patients found similar results[18]. There can be a transitory elevation of $\alpha \mathrm{FP}$ in patients with cirrhosis and exacerbations of infectious hepatitis[37]. Alpha-fetoprotein levels are not elevated in many patients with HCC, which makes the transversal measuring of the $\alpha \mathrm{FP}$ elevation not an optimal diagnostic test. Moreover the clinical usefulness of alpha-fetoprotein in hepatocellular carcinoma management is still being debated [38].

We observed that an $\alpha \mathrm{FP}$ monthly average progression rate $\geq 7 \mathrm{ng} / \mathrm{mL} / \mathrm{month}$ of at least 3 determinations, has a sensitivity and specificity of 71.4 and $100 \%$, respectively. The elevation of $\alpha \mathrm{FP}$ after one month of follow-up sometimes did not show any changes; we realized that 3 determinations were required in order to have a more accurate test.

The $\alpha$ FP progression rate and a tumor-suggestive image together - could be employed to diagnose HCC. This approach could be of special interest in patients with LC and clinical suspicious of HCC, who are not candidates neither for biopsy nor for surgical treatment and who do not reach an $\alpha \mathrm{FP}$ level $\geq 200 \mathrm{ng} / \mathrm{mL}$; they could benefit of being diagnosed with HCC and initiate treatment without waiting for $\alpha F P$ levels to reach a value $\geq 200$ or $\geq 400 \mathrm{ng} /$ 
Table 2: Clinical and pathological factors associated with the levels of $\alpha \mathrm{FP}$ in patients with hepatocellular carcinoma (HCC).

\begin{tabular}{|c|c|c|}
\hline Associated Factors & Levels of FP $\alpha(\mathrm{ng} / \mathrm{mL})$ & $P$ \\
\hline \multicolumn{3}{|l|}{ Child-Pugh Score } \\
\hline$A$ & $|7| \pm 34$ & 0.74 \\
\hline $\mathrm{B}$ & $229 \pm 73$ & \\
\hline $\mathrm{C}$ & $211 \pm 80$ & \\
\hline \multicolumn{3}{|l|}{ Mean age } \\
\hline$<60$ years & $267 \pm 64$ & 0.78 \\
\hline$>60$ years & $132 \pm 19$ & \\
\hline \multicolumn{3}{|l|}{ Gender } \\
\hline Female & $164 \pm 43$ & 0.49 \\
\hline Male & $238 \pm 53$ & \\
\hline \multicolumn{3}{|l|}{ Etiology } \\
\hline $\mathrm{HBV}$ & $368 \pm 36$ & 0.16 \\
\hline $\mathrm{HCV}$ & $137 \pm 23$ & \\
\hline Cryptogenic/autoimmune & $52 \pm 23$ & \\
\hline Alcoholic & $275 \pm 99$ & \\
\hline Undetermined or absent & $258 \pm 90$ & \\
\hline \multicolumn{3}{|l|}{ Degree of differentiation } \\
\hline Well & $167 \pm 29$ & 0.16 \\
\hline Moderate & $271 \pm 87$ & \\
\hline Poor & $140 \pm 10$ & \\
\hline \multicolumn{3}{|l|}{ Tumor Size } \\
\hline$<5 \mathrm{~cm}$ & $267 \pm 64$ & 0.66 \\
\hline$>5 \mathrm{~cm}$ & $132 \pm 19$ & \\
\hline
\end{tabular}

mL. Many patients with a suggestive image of HCC can not be biopsied due either to coagulation abnormalities or location of the tumor or due to the presence of massive ascites among other causes; also, many patients do not reach the value of 200 or $400 \mathrm{ng} / \mathrm{mL}$ (in our study $63.7 \%$ and $79.8 \%$, respectively), reason why the progressive elevation of $\alpha \mathrm{FP}$ could help to establish the diagnosis without the need of biopsy and could allow the inclusion of these patients to treatment study protocols. On the other hand, the continuous increase of aFP should induce the

Table 3: Sensitivity and Specificity for the transversal determinations of $\alpha$ FP for the diagnosis of hepatocellular carcinoma (HCC)

\begin{tabular}{|c|c|c|}
\hline$\alpha \mathrm{FP}(\mathrm{ng} / \mathrm{mL})$ & Sensitivity (\%) & Specificity (\%) \\
\hline 0.3 & 99.5 & 0 \\
\hline 2.5 & 92.2 & 29.7 \\
\hline 5.1 & 83.9 & 57 \\
\hline 7.5 & 77.7 & 72 \\
\hline 10.2 & 71 & 88 \\
\hline 15.5 & 64.2 & 96 \\
\hline 20.3 & 60.6 & 96 \\
\hline 25.6 & 58.5 & 96 \\
\hline 51.35 & 51.8 & 99 \\
\hline 72.5 & 48.7 & 99 \\
\hline 98.65 & 47.2 & 99 \\
\hline III & 45.6 & 99 \\
\hline 130 & 43 & 99 \\
\hline 160 & 38.9 & 100 \\
\hline 190 & 36.3 & 100 \\
\hline 215 & 34.7 & 100 \\
\hline 280 & 24.4 & 100 \\
\hline 330 & 21.8 & 100 \\
\hline 395 & 20.2 & 100 \\
\hline 415 & 18.7 & 100 \\
\hline
\end{tabular}


Table 4: Sensitivity and Specificity for the progression rate of $\alpha$ FP

\begin{tabular}{|c|c|c|}
\hline Progression rate (ng/mL/month) & Sensitivity (\%) & Specificity (\%) \\
\hline-3.43 & 100 & 0 \\
\hline 0.1065 & 95.2 & 56 \\
\hline 0.2335 & 92.1 & 70 \\
\hline 0.66 & 87.3 & 82 \\
\hline 0.94 & 84.1 & 85 \\
\hline 1.6 & 81 & 89 \\
\hline 2.15 & 81 & 94 \\
\hline 2.64 & 81 & 95 \\
\hline 3.01 & 79.4 & 95 \\
\hline 3.29 & 79.4 & 97 \\
\hline 4.04 & 77.8 & 97 \\
\hline 4.75 & 77.8 & 99 \\
\hline 5.07 & 76.2 & 99 \\
\hline 5.47 & 74.6 & 99 \\
\hline 5.84 & 71.4 & 100 \\
\hline 8.87 & 66.7 & 100 \\
\hline 10.8 & 65.1 & 100 \\
\hline 16.83 & 52.4 & 100 \\
\hline 20.4 & 46 & 100 \\
\hline 28.94 & 38.1 & 100 \\
\hline
\end{tabular}

start of research protocols for HCC and eventually enrollment of these patients in a transplantation program even before the tumor becomes detectable.

There are few existing studies that evaluate the utilization of serial determinations of $\alpha \mathrm{FP}$ for the diagnosis of HCC and none compares it to the transversal determination of $\alpha \mathrm{FP}$ at its best specificity level $(\geq 200 \mathrm{ng} / \mathrm{mL})[18,39,40]$. A study demonstrated that a fast and sudden elevation of $\alpha F P$ in patients with liver lesions detected more HCC when compared to other elevation patterns in patients with cirrhosis and hepatic lesions[41]. Many studies have been done to increase the specificity of the measurement of $\alpha \mathrm{FP}$ for the diagnosis of HCC depending on its binding capacity to different molecules; however its use is expensive and it is not widely available[2,42].

Even though high $\alpha \mathrm{FP}$ levels may be more indicative of HCC in patients with LC without viral infection [9], the type of viral infection (HBV or HCV) does not seem to have a direct influence on the serum $\alpha$ FP levels in patients with HCC $[21,43]$. A limitation of this study are the differences in etiology between both study groups, mainly regarding HBV patients, which could cause the differences in the $\alpha \mathrm{FP}$ levels. Also, since it is a retrospective study, it was not possible to match both groups from the beginning. Prospective studies need to be done in order to corroborate our findings and to perform a cost-benefit analysis of this test. Nevertheless, these studies might be difficult to perform; as a matter of fact, if we consider that approximately $5 \%$ of the patients with viral hepatitis and LC develop HCC within a year, the number of patients with LC needed to carry out such studies is rather large.

\section{Conclusion}

In conclusion, the average progressive elevation of $\alpha \mathrm{FP} \geq 7$ $\mathrm{ng} / \mathrm{mL} / \mathrm{month}$ and a tumor-suggestive image - together in patients with LC could be a very useful tool for the detection of HCC, especially in those patients without a transversal $\alpha$ FP elevation $\geq 200 \mathrm{ng} / \mathrm{mL}$.

Table 5: Positive Predictive Value (PPV) and Negative Predictive Value (NPV) for the diagnosis of HCC with $\alpha$ FP values $\geq 200, \alpha$ FP values $\geq 400 \mathrm{ng} / \mathrm{mL}$ and with the progressive elevation of $\alpha \mathrm{FP}$ of $5 \mathrm{ng} / \mathrm{mL}$ with a prevalence of 5 and $10 \%$.

\begin{tabular}{llll}
\hline$\alpha$ FP & HCC Prevalence (\%) & PPV (\%) & NPV (\%) \\
\hline $200 \mathrm{ng} / \mathrm{ml}$ & 10 & 97.58 & 93.4 \\
$\geq 400 \mathrm{ng} / \mathrm{ml}$ & 5 & 95.03 & 96.7 \\
& 10 & 95.7 & 91.86 \\
Elevation $\geq 7 \mathrm{ng} / \mathrm{ml} / \mathrm{month}$ & 5 & 91.4 & 95.97 \\
& 10 & 98.7 & 96.92
\end{tabular}




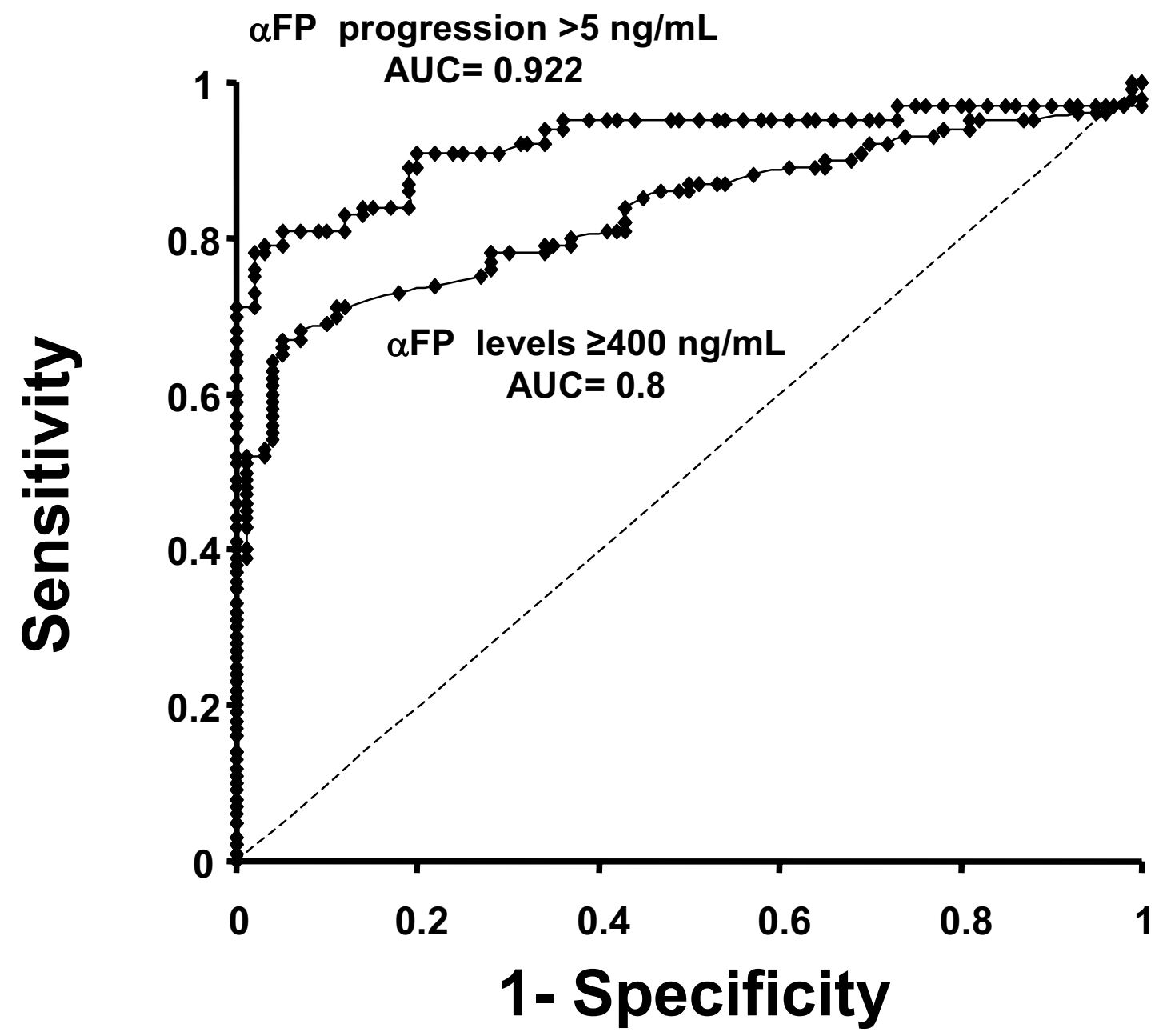

Figure I

ROC curve for the progressive elevation of $\alpha \mathrm{FP}$ and $\alpha \mathrm{FP}$ levels. The area under the curve for the progressive elevation of $\alpha \mathrm{FP}$ is significantly greater than the area under the curve for $\alpha$ FP levels $(p<0.05)$. (AUC = Area Under the Curve).

Table 6: Comparison of sensitivity and specificity of the $\alpha$ FP levels for the diagnosis of hepatocellular carcinoma (HCC) of several studies

\begin{tabular}{|c|c|c|c|c|c|c|c|c|c|c|c|c|}
\hline \multirow[t]{2}{*}{ Authors } & \multicolumn{2}{|c|}{$\alpha \mathrm{FP} 10-16(\mathrm{ng} / \mathrm{mL})$} & \multicolumn{2}{|c|}{$\alpha \mathrm{FP} 20(\mathrm{ng} / \mathrm{mL})$} & \multicolumn{2}{|c|}{$\alpha \mathrm{FP} \quad \mathrm{O} 00(\mathrm{ng} / \mathrm{mL})$} & \multicolumn{2}{|c|}{$\alpha \mathrm{FP} 200(\mathrm{ng} / \mathrm{mL})$} & \multicolumn{2}{|c|}{$\alpha \mathrm{FP} 300(\mathrm{ng} / \mathrm{mL})$} & \multicolumn{2}{|c|}{$\alpha \mathrm{FP} 400(\mathrm{ng} / \mathrm{mL})$} \\
\hline & $\mathrm{S}(\%)$ & $E(\%)$ & S (\%) & E (\%) & $\mathrm{S}(\%)$ & E (\%) & $\mathrm{S}(\%)$ & $E(\%)$ & S (\%) & $E(\%)$ & S (\%) & $E(\%)$ \\
\hline Oka et al 1994 & & & 39 & 76 & 13 & 97 & & & & & & \\
\hline Pateron et al 1994 & 50 & 86 & & & 21 & 93 & & & & & & \\
\hline Peng et al 1999 & & & 65 & 87 & & & 45 & 100 & & & & \\
\hline Tong et al 200I & & & 41 & 94 & & & & & & & & \\
\hline Trevisani et al 2001 & 62.4 & 89.4 & 60 & 90.6 & 31.2 & 98.8 & 22 & 99 & 22.4 & 99.4 & 17.1 & 99.4 \\
\hline Gebo et al 2002* & & & 60 & & & & & & & & $0-64$ & 100 \\
\hline Nguyen et al 2002 & 78.4 & 61.1 & 63 & 80 & 41.4 & 97.3 & 32 & 100 & & & & \\
\hline Gupta et al 2003* & & & $4 I-65$ & $80-94$ & & & & & & & & \\
\hline Farinati et al 2006 & & & 54 & & & & & & & & 18 & \\
\hline Arrieta $2007^{+}$ & 63.2 & 95.9 & 60.6 & 95.9 & 47.2 & 99 & 36.3 & 100 & 22.8 & 100 & 20.2 & 100 \\
\hline
\end{tabular}

$\mathrm{S}=$ sensitivity, $\mathrm{E}=$ specificity.

$*$ Literature review

+ Present study 


\section{Competing interests}

The author(s) declare that they have no competing interests.

\section{Authors' contributions}

BC, AVR, NHP and DME reviewed medical records and participated in the design. DME helped to draft the manuscript and contributed to the statistical analysis. OA conceived of the study, and participated in its design and coordination, performed the statistical analysis and helped to draft the manuscript. All authors read and approved the final manuscript.

\section{References}

I. El-Serag HB: Hepatocellular carcinoma: An Epidemiologic View. J Clin gastroenterol 2002, 35(Suppl 2):S72-S78.

2. Hasan F, Jeffers LJ, De Medina M, Reddy KR, Parker T, Schiff ER, Houghton M, Choo QL, Kuo G: Hepatitis-C associated hepatocellular carcinoma. Hepatology 1990, | 2:589-59|.

3. Aguayo A, Patt YZ: Liver cancer. Clin Liver Dis 200I, 5:479-507.

4. Harada T, Shigeta K, Noda K, Fukumoto Y, Nishimura H, Mizuta M, Takemoto $\mathrm{T}$ : Clinical implications of slpha-fetoprotein in liver cirrhosis: five-year follow-up study. Hepatogastroenterol 1980, 27(3):169-75.

5. Rodriguez-Diaz JL, Rosas-Camargo V, Vega-Vega O, MoralesEspinosa D, Martínez-Tlahuel JL, Gamboa-Domínguez A, Arrieta O: Clinical and Pathological Factors associated with the development of hepatocellular carcinoma in patients with hepatitis virus-related cirrhosis: a long-term follow-up study. Clin Oncol 2007 in press.

6. Arrieta O, Rodríguez-Díaz J, Rosas-Camargo V, Morales-Espinosa D, Ponce de León S, Kershenobich D, León-Rodríguez E: Colchicine delays the development of hepatocellular carcinoma in patients with hepatitis virus related-liver cirrhosis. Cancer 2006, I07(8): 1852-1858.

7. Mizejewski G]: Levels of alpha-fetoprotein during pregnancy and early infancy in normal and disease states. Obstet Gynecol Surv 2003, 58:804-826.

8. Farinati F, Marino D, De Giorgio M, Baldan A, Cantarini M, Cursaro C, Rapaccini G, Del Poggio P, Di Nolro M, Benvegnù L, Zoli M, Borzio F, Bernardi M, Trevisani F: Diagnostic and prognostic role of $\alpha$ fetoprotein in hepatocellular carcinoma: Both or neither? Am J Gastroenterol 2006, 10 I:524-32.

9. Trevisani F, D'Intino PE, Morselli-Labate AM: Serum $\alpha$-fetoprotein for diagnosis of hepatocellular carcinoma in patients with chronic liver disease: influence of $\mathrm{HbsAg}$ and anti-HCV status. J Hepatology 200I, 34:570-575.

10. Bruix J, Sherman M: Management of hepatocellular carcinoma. AASLD Practice Guidelines. Hepatology 2005, 42(5):2208-2236.

II. Talwalkar JA, Gores G]: Diagnosis and staging of hepatocellular carcinoma. Gastroenterology 2004, I27(SuppI I):SI26-SI32.

12. Commissione Epatocarcinoma dell'Associazione Italiana per lo Studio del Fegato. In Epatocarcinoma: Linee Guida per la Diagnosi e la Terapia Bologna: Tipografia Moderna; 1998:235-86.

13. Trape J, Botargues JM, Porta F, Ricos C, Badal JM, Salinas R, Sala M, Roca A: Reference Change Value for $\alpha$-Fetoprotein and Its Application in Early Detection of Hepatocellular Carcinoma in Patients with Hepatic Disease. Clin Chem 2003, 49(7): I209-II.

14. Lerose R, Molinari R, Rocchi E, Manenti F, Villa E: Prognostic features and survival of hepatocellular carcinoma in Italy. Eur J Cancer 2001, 37:239-245.

15. Sarasin FP, Giostra E, Hadengue A: Cost-effectiveness of screening for detection of small hepatocellular carcinoma in Western patients with Child-Pugh Class A cirrhosis. Am J Med 1996, 1 $01: 422-434$.

16. Bolondi L: Surveillance programme of cirrhotic patients for early diagnosis and treatment of hepatocellular carcinoma: a cost effectiveness analysis. Gut 200I, 48:25I-259.
17. Yuen MF, Lai CL: Screening for hepatocellular carcinoma: survival benefit and cost-effectiveness. Ann Oncol 2003, 14: I463-1467.

18. Oka H, Tamori A, Kuroki T, Kobayashi K, Yamamoto S: Prospective study of $\alpha$-fetoprotein in cirrhotic patients monitored for development of hepatocellular carcinoma. Hepatology 1994, 19:6I-66.

19. Keighley MR, Girdwood RW, Wooler GH, lonescu MI: Long-term results of surgical treatment for bleeding oesophageal varices in children with portal hypertension. $\mathrm{Br} J$ Surg 1973, 60(8):64I-6.

20. Christensen E, Schlichting P, Fauerholdt L, Gluud C, Andersen PK Juhl E, Poulsen H, Tygstrup N: Prognostic value of Child-Turcotte criteria in medically treated cirrhosis. Hepatology 1984 4(3):430-5.

21. Nomura F, Ohnishi K, Tanabe Y: Clinical Features and prognosis of hepatocellular carcinoma with reference to serum alphafetoprotein levels. Cancer 1989, 64: I700-I707.

22. Colombo M, de Franchis R, Del Ninno E, Sangiovanni A, De Fazio C, Tommasini M, Donato MF, Piva A, Di Carlo V, Dioguardi N: Hepatocellular carcinoma in Italian patients with cirrhosis. $N$ Engl J Med 1991, 325:675-80.

23. Zaman SN, Melia WM, Johnson RD, Johnson PJ, Portmann BC, Williams R: Risk factors in development of hepatocellular carcinoma in cirrhosis: Prospective study of 613 patients. Lancet 1985, I 5: I357-I359.

24. Tangkijvanich P, Anukulkarnkusol, Sueangool P, Lertmaharit S, Hanvivatvong $O$, Kullavanijaya $P$, Poovorawan $Y$ : Clinical characteristics and prognosis of hepatocellular carcinoma. I Clin Gastroenterol 2000, 3 1:302-308.

25. Trevisani F, D'Intino PE, Caraceni P, Pizzo M, Stefanini GF, Mazziotti A, Grazi GL, Gozzetti G, Gasbarrini G, Bernardi M: Etiologic factors and clinical presentation of hepatocellular carcinoma. Cancer 1995, 75:2220-2232.

26. Lee H-S, Chung YH, Kim CY: Specificities of serum $\alpha$-fetoprotein in HbsAg+ and HbsAg-patients in the diagnosis of hepatocellular carcinoma. Hepatology 1991, 14:68-72.

27. Kew M: Alpha-fetoprotein in primary liver cancer and other diseases. Gut 1974, 15:8|4-82I.

28. Bolondi L, Benzi G, Santi V, Gaiani S, Li Bassi SL, Zironi G, Mazziotti A, Sama C, Grigioni W, Gozzetti G: Relationship between alphafetoprotein serum levels, tumour volume and growth rate of hepatocellular carcinoma in a western population. Ital J Gastroenterol 1990, 22(4): 190-4.

29. Mok TS, Yeo W, Yu S, Lai P, Chan HL, Chan AT, Lau JW, Wong H, Leung N, Hui EP, Sung J, Koh J, Mo F, Zee B, Johnson PJ: An extensive surveillance program detected a high incidence of hepatocellular carcinoma among hepatitis B virus carries with abnormal alpha-fetoprotein levels or abdominal ultrasonography results. J Clin Oncol 2005, 23(3 I):804I-7.

30. Yu EW, Chie WC, Chen TH: Does screening or surveillance for primary hepatocellular carcinoma with ultrasonography improve the prognosis of patients? Cancer J 2004, I0(5):3 I 7-25

3I. Izumi R, Shimizu K, Kiriyama M, Hashimoto T, Urade M, Yagi M, Mizukami Y, Nonomura A, Miyazaki I: Alpha-fetoprotein production by hepatocellular carcinoma is prognostic of poor patient survival. J Surg Oncol 1992, 49(3): 15I-5.

32. Peng YC, Chan CS, Chen GH: The effectiveness of serum alphafetoprotein level in anti-HCV positive patients for screening hepatocellular carcinoma. Hepatogastroenterology 1999, 46:3208-32II.

33. Tong Mj, Blatt LM, Kao VW: Surveillance for hepatocellular carcinoma in patients with chronic viral hepatitis in the United States of America. J Gastroenterol Hepatol 200I, 16:553-559.

34. Nguyen MH, Keeffe EB: Screening for hepatocellular carcinoma. Clin Gastroenterol 2002, 35(Suppl 2):S86-S9I.

35. Gebo KA, Chander G, Jenckes MW, Ghanem KG, Herlong HF Torbenson MS, El-Kamary SS, Bass EB: Screening tests for hepatocellular carcinoma in patients with chronic hepatitis C: a systematic review. Hepatology 2002, 36:S84-S92.

36. Gupta S, Bent S, Kohlwes J: Test Characteristics of $\alpha$-Fetoprotein for Detecting hepatocelullar carcinoma in patients with hepatitis C. Ann Intern Med 2003, 139:46-50.

37. Pateron D, Ganne N, Trinchet JC, Aurousseau MH, Mal F, Meicler C, Coderc E, Reboullet $P$, Beaugrand M: Prospective study of screen- 
ing for hepatocellular carcinoma in Caucasian patients with cirrhosis. J Hepatol 1994, 20:65-71.

38. Sherman M: Alphafetoporotein: an obituary. Journal of Hepatology 200I, 34:603-605.

39. Di Bisceglie A, Hoofnagle JH: Elevations in serum alpha-fetoprotein levels in patients with chronic hepatitis B. Cancer 1989, 64:2117-20.

40. Heyward WL, Lanier AP, McMahon BJ, Fitzgerald MA, Kilkenny S, Paprocki TR: Early detection of primary hepatocellular carcinoma. JAMA 1985, 254:3052-3054.

41. Kuwuahara T, Sakai, Majima Y, Hirai K, Tanikawa K: Serial changes in serum alpha-fetoprotein prior to detection of hepatocellular carcinoma in liver cirrhosis. Hepatogastroenterol 1993, 40:347-35I.

42. Sato $Y$, Nakata K, Kato $Y$, Shima M, Ishii N, Koji T, Taketa K, Endo $Y$, Nagataki S: Early recognition of hepatocellular carcinoma based on altered profiles of alpha-fetoprotein. $N$ Engl J Med 1993, 328: $1802-1806$.

43. Cedrone A, Covino M, Caturelli E, Pompili M, Lorenzelli G, Villani $M R$, et al: Utility of $\alpha$-fetoprotein (AFP) in the screening of patients with virus-related chronic liver disease: does different viral etiology influence AFP levels in HCC? A study in $\mathbf{3 5 0}$ Western patients. Hepatogastroenterology 2000, 47:1654-1658.

\section{Pre-publication history}

The pre-publication history for this paper can be accessed here:

http://www.biomedcentral.com/1471-2407/7/28/prepub

Publish with Biomed Central and every scientist can read your work free of charge

"BioMed Central will be the most significant development for disseminating the results of biomedical research in our lifetime. "

Sir Paul Nurse, Cancer Research UK

Your research papers will be:

- available free of charge to the entire biomedical community

- peer reviewed and published immediately upon acceptance

- cited in PubMed and archived on PubMed Central

- yours - you keep the copyright

Submit your manuscript here:

http://www.biomedcentral.com/info/publishing_adv.asp 